\title{
Shopping behaviour of e - commerce customers on the example of generation $Z$
}

\author{
Dominik Laitkep ${ }^{1}$, Katarina Repkova Stofkova ${ }^{1, *}$ \\ ${ }^{1}$ University of Zilina, Faculty of Operation and Economics of Transport and Communications, \\ Univerzitna 1, 01026 Zilina, Slovakia
}

\begin{abstract}
Research background: In today's competition markets and different types of customers, it is difficult to achieve a competitive advantage for merchants without knowing the shopping behaviour or intentions of customers. We can classify online store customers into many categories, but we have chosen a category - Generation Z.

Purpose of the article: Generation $\mathrm{Z}$ can be generally defined as the technically most advanced generation of the entire population. This generation represents demanding customers who seek experiences and shop the mostly online. Generation $\mathrm{Z}$ members have relatively high ambitions regarding their careers, lives and they know exactly what, where and how they shop. The aim of this article is to present key factors influencing purchasing behaviour of Generation $\mathrm{Z}$ in Slovakia.

Methods: Methods were used to meet the aim of the paper, to present the results of the author's primary research, processed by reducing the number of attributes influencing purchasing behavior using factor analysis. The target group of primary research respondents was born between 1997 and 2012.

Findings \& Value added: Purchasing behavior of the $\mathrm{Z}$ generation is mainly influenced by design of the website, the importance of delivery methods together with the possibility of online payment, reviews of merchants and shopping at a well-known seller. An interesting finding is Generation Z's lack of interest in a new wave of trends influencing shopping preferences through popular people on the Internet, called influencers.
\end{abstract}

Keywords: consumer behavior; factor analysis; e-commerce; social networks

JEL Classification: $D 12 ; D 9 ; E 21$

\section{Introduction}

In today's competition and different types of customers, it is difficult to achieve a competitive advantage without knowing the shopping behaviour of customers. At first place, every company things, it's easy to predict what customers want, need, what they're looking for.

\footnotetext{
*Corresponding author: katarina.stofkova@,fpedas.uniza.sk
} 
However, not every company knows the real needs of customers by its own conjectures and assumptions. There are certain factors that influence shopping behaviour and if the company knows them, company can use them like advantage (Valaskova et al., 2021).

In order to improve the current situation, ever higher demands are placed on companies in the area of improving their functioning and the quality of products and services, but also on their marketing. If companies want to succeed in markets with strong competitive pressure, they must also focus on marketing communication and strive to achieve the status of so-called excellence.

One possible way to achieve this is through innovation. Focusing on the quality of communication is a basic prerequisite for gaining a competitive advantage for the company not only by reducing the costs resulting from ineffective advertising, but also by gaining more customers based on more effective information about the services provided. (Kubas et al., 2017)

The process of globalisation creates higher demand on the adoption of highly flexible innovative solutions. The globalisation and technological development bring a specific form of network business. (Gasova and Stofková, 2017) The global competitiveness of business has a different dimension, as the competitiveness of a business also depends to a large extent on the comparative advantages provided by national authorities. (Zilincikova and Stofkova, 2021)

Shopping habits and behaviour are naturally dependent on the age group and also change over time and it is differs from country to country.

Knowledge of generations of consumers is one of the prerequisites for correct segmentation, it is a key identifier in addressing real and potential consumers. In marketing, generations are intensively discussed and great emphasis is placed on them. The preferences of individual generations influence their shopping behaviour, but to really influence it requires a thorough knowledge of the addressed generation and often also the specifics that are related to the development in individual countries. (Smolka, 2019)

Generation $\mathrm{Z}$ is defined differently by individual authors. Some claim that this generation is dated from the year 2000 to the present, others claim that it includes only the population that was born between 1994 and 2004 (Cismariu et al., 2019). Other authors claim that it is the generation born from 1997 to of 2012 (Dolot, 2018). We are working in our contribution with generation, which was born between 1997 to 2012. Generation Z can generally be defined as the most technically advanced generation among the entire population.

Among the characteristics of generation $\mathrm{Z}$ we can include, for example:

- Have high demands without taking much effort;

- The Internet is part of their daily lives;

- Theirs instability in employment leads to frequent job changes;

- High skill of the online environment;

- Online shopping;

- Dependence on information and communication technologies;

- Inability to focus on one object.

Like every generation, Generation $\mathrm{Z}$ has certain positive and negative aspects (Nadanyiova et al., 2020). Individual selected positives and negatives of generation $Z$ can be seen in the following table No. 1.

Like every generation, Generation $\mathrm{Z}$ has certain positive and negative aspects (Munsch, 2021). Individual selected positives and negatives of generation $Z$ can be seen in the following table No. 1. After defining the $Z$ generation, it is necessary to focus on the purchasing behaviour of this generation. In this scientific article, we focus on monitoring the purchasing behaviour of the $\mathrm{Z}$ generation. 
Table 1. Generation Z Specifics

\begin{tabular}{|c|c|}
\hline Positive aspects of Generation $\mathbf{Z}$ & Negative aspects of Generation $\mathbf{Z}$ \\
\hline $\begin{array}{c}\text { Know how for working quickly and } \\
\text { efficiently with information. }\end{array}$ & Loss of discreet behaviour. \\
\hline They can make social contacts quickly. & Feeling of maximum independence. \\
\hline They are team-oriented. & Living their life in the virtual world. \\
\hline They can perform several activities at once. & High self-confidence. \\
\hline
\end{tabular}

Source: Specifics of online behaviour of the $\mathrm{Z}$ generation. Available online: $<$ https://www.mins.sk/specifika-online-spravania-sa-generacie-Z>. (2021, own processing)

By shopping behaviour we mean the behaviour of an individual or the whole household who buys products and services for personal consumption which are participates in the consumer market. The basis of shopping behaviour is precisely the values and especially the needs which guides the individual in obtaining certain values. These values stimulate the form and tendencies in consumer behaviour as well as in the shopping activities of various social groups. For this reason, it is important to analyse a particular social group, such as Generation Z, and to monitor their given various factors which stimulate consumer behaviour, which is then reflected in the various purchasing activities of that generation

Scientific research by scientist Dimock describes 3 characteristic trends that define Generation $\mathrm{Z}$ as consumers. These trends include:

1. Interest in new technologies and Security;

2. Easy use of product/service;

3. Temporary escape from the reality which they face. (Dimock, 2021)

Generation $\mathrm{Z}$ is different from previous generations. For this reason we decided to monitor the shopping behaviour of individuals aged 15 to 22 within Generation Z, because it can be very interesting to examine what factors of shopping behaviour affect this generation and how is this reflected in their shopping activities.

\section{Methods}

The aim of the article is to point out key factors which influencing the purchase process, especially on the Internet for Generation Z, Slovaks, using social networks. The individual reduced factors are formed by the attributes that the potential customer will encounter when they deciding to make a purchase. Factors provide identification of key elements that companies should focus on in this particular case. (Johnson and Wichern, 2007). Factor analysis is applied on the open source platform, the PSPP software solution (Statistika PSPP, 2021).

To achieve this goal, it was necessary to use methods, which are the method of excerpting, method of analysis, primary research, factor analysis, method of induction and deduction. (Herbak et. al. 2017).

We used the excerpting method to obtain theoretical knowledge of the researched issues. We used the method of analysis in the analysis of the current state, when we monitored secondary research. Subsequently, the primary research was carried out, which was focused on finding out what attributes influence the shopping behaviour of Generation $\mathrm{Z}$ customers in the Slovak Republic.

After obtaining the answers of customer respondents, an exploratory factor analysis was performed, which presents the key factors influencing the purchase of the addressed target group. In the case of this paper, e-commerce customers were represented by respondents of Generation Z. The respondents was consisted of 844 respondents from 15 to 22 years of age with an average age of 20.34 years using social networks. The presented results are relate to 
the conditions of Slovak e-commerce. To calculate the minimum sample size, it was necessary to find out how many inhabitants, men in the Slovak Republic are aged 15-22 years. As of March 18, 2021, the number of selected inhabitants in the Slovak Republic is 444,668 (StatDAT, 2021). After determination of inhabitants of the sample spectrum, we used the following formula to calculate large basic files.

$$
n \geq t_{1-\frac{\alpha}{2}} * \frac{\sigma^{2}}{\Delta^{2}}
$$

Where: $\mathrm{n}$ - is the minimum sample size (minimum number of respondents); $\mathrm{N}$ - Value of basic sample size; $\mathrm{t} 2(1-\alpha / 2)$ - the critical value determined from the tables (critical values of the normalized normal distribution) $; \sigma 2$ - is the spread calculated from the standard deviation; $\Delta$ - the maximum allowable margin of error.

After choosing right formula, we calculated it.

$$
n \geq \frac{1,96^{2}}{0,04^{2}} x 0,5^{2}=600,25 \doteq 600 \text { respondendents }
$$

After substituting the values into the formula for calculating the sample of large basic files, we found that at $95 \%$ confidence and 5\% error range, the minimum sample is 600 respondents. During the primary survey, we managed to address up to 690 respondents, users of social networks whose we can classify as generation $\mathrm{Z}$ based on their age. We can conclude that the requirement to meet the minimum sample size has been met. Subsequently, factor analysis was used to evaluate the results of the primary research, when seven factors were identified through this analysis. Methods such as induction and deduction were used to evaluate the results and individual recommendations.

\section{Results}

The primary research conducted in the form of a questionnaire yielded results in the form of answers to questions from respondents. There were twenty-five questions which are presenting the attributes determined on the basis of a situation analysis and a primary survey. The questions concerned various online as well as offline communication channels and sales and marketing methods, which are shown in table No. 2, while the respondent could choose between the answer on the liqueur scale from 1-5, when 1 represented a complete disinterest and 5 a maximum interest. (Svabova and Kramarova, 2021).

Table 2. Questions from form.

\begin{tabular}{|c|c|}
\hline Questions - Attributes & Value \\
\hline Importance of Social networks & 1,00 \\
\hline Quality of posts published on social networks & 1,00 \\
\hline Truthfulness of contributions published on social networks & 1,00 \\
\hline Advertising posts from influencers & 1,00 \\
\hline Reviews from influencers & 1,00 \\
\hline Promo code for purchases from influencers & 1,00 \\
\hline Promotions & 1,00 \\
\hline Promo code for first purchase & 1,00 \\
\hline Activities of companies on social network & 1,00 \\
\hline Possibility to buy in stone shops & 1,00 \\
\hline Online shopping & 1,00 \\
\hline Webpage design & 1,00 \\
\hline Impulsive shopping & 1,00 \\
\hline
\end{tabular}




\begin{tabular}{|c|c|}
\hline Methods of delivery of ordered goods & 1,00 \\
\hline Free delivery of ordered goods & 1,00 \\
\hline Offline comercials & 1,00 \\
\hline Mobile shopping & 1,00 \\
\hline Sustainability of business and responsibility of companies & 1,00 \\
\hline YouTube Companies Activities & 1,00 \\
\hline Companies Reviews & 1,00 \\
\hline Shopping at famous companies & 1,00 \\
\hline Cash payment & 1,00 \\
\hline Online payment & 1,00 \\
\hline Crypto payment & 1,00 \\
\hline Newsletters & 1,00 \\
\hline
\end{tabular}

Source: Authors (2021)

\subsection{Determination of the number of factors}

The number of generated factors is graphically interpreted using the following figure No. 1, which shows us the real number of potential factors, which is expressed by a graph - scree plot. The scree plot is used to determine other interpretable factors with their own numbers and variance.

The $\mathrm{Y}$ axis expresses the eigenvalue. The eigenvalue represents the number of a specific factor, which tells us how much variability a given factor represents from the overall system of monitored variables (Madlenakova et. al., 2019).Factors from the largest to the smallest factor are arranged on the X-axis. Figure 1 graphically shows all the specified attributes, specifically 25 potential factors.

In the case of our Figure 1, we identify 25 potential factors. As significant factors are only those with y greater than 1, we have identified 8 key factors. These 8 factors can be considered as significant.

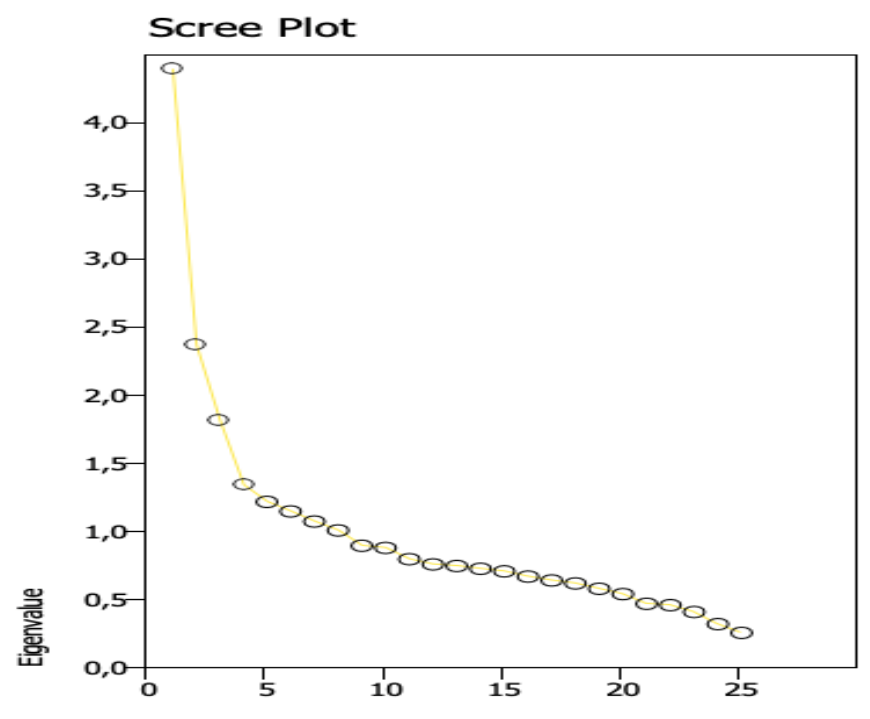

Figure 1. Scree Plot

Source: Authors (2021) 


\subsection{Eigenvalues and their percentage variability of identified factors}

The self-value of the first factor is 4.4\%. (See the Total Eigenvalue column in Table 3). Eight factors explain $57.64 \%$ of the variability of all variables. The overall percentage of variability explained by these factors is appropriate. In our case, however, we will be working with the Rotation Sum of Squared Loadings where the First factor is $1.87 \%$ and eight factors explain $51.63 \%$ of the variability of all variables.

After applying the rotation, it is possible to identify the values of correlation to individual factors and determine them so that if it is possible to identify their load on a given factor by the relevant variable (Duris et al., 2021).

Table 3. Total Variance Explained.

\begin{tabular}{|c|c|c|c|c|c|c|}
\hline \multirow{2}{*}{ Component } & \multicolumn{3}{|c|}{ Initial Eigenvalues } & \multicolumn{3}{|c|}{$\begin{array}{c}\text { Rotation Sum of Squared } \\
\text { Loadings }\end{array}$} \\
\hline & Total & $\begin{array}{c}\text { \% of } \\
\text { Variance }\end{array}$ & $\begin{array}{c}\text { Cumulative } \\
\%\end{array}$ & Total & $\begin{array}{c}\text { \% of } \\
\text { Variance }\end{array}$ & $\begin{array}{c}\text { Cumulative } \\
\%\end{array}$ \\
\hline 1. & 4,40 & 17,60 & 17,60 & 1,87 & 7,48 & 7,48 \\
\hline 2. & 2,38 & 9,50 & 27,10 & 2,12 & 8,49 & 15,97 \\
\hline 3. & 1,82 & 7,27 & 34,37 & 1,79 & 7,15 & 23,12 \\
\hline 4. & 1,35 & 5,39 & 39,76 & 2,08 & 8,31 & 31,43 \\
\hline 5. & 1,22 & 4,89 & 44,65 & 2,09 & 8,35 & 39,78 \\
\hline 6. & 1,15 & 4,61 & 49,27 & ,32 & 1,30 & 41,08 \\
\hline 7. & 1,08 & 4,32 & 53,59 & 2,11 & 8,44 & 49,52 \\
\hline 8. & 1,01 & 4,06 & 57,64 & ,53 & 2,11 & 51,63 \\
\hline 9. & ,90 & 3,61 & 61,25 & & & \\
\hline 10. & ,89 & 3,54 & 64,79 & & & \\
\hline 11. &, 80 & 3,21 & 68,01 & & & \\
\hline 12. &, 77 & 3,06 & 71,07 & & & \\
\hline 13. &, 75 & 3,01 & 74,08 & & & \\
\hline 14. &, 73 & 2,93 & 77,01 & & & \\
\hline 15. &, 71 & 2,86 & 79,87 & & & \\
\hline 16. & ,68 & 2,70 & 82,57 & & & \\
\hline 17. &, 65 & 2,59 & 85,16 & & & \\
\hline 18. & ,63 & 2,50 & 87,67 & & & \\
\hline 19. & ,59 & 2,35 & 90,01 & & & \\
\hline 20. & ,55 & 2,19 & 92,20 & & & \\
\hline 21. & ,48 & 1,91 & 94,11 & & & \\
\hline 22. & ,47 & 1,87 & 95,97 & & & \\
\hline 23. &, 42 & 1,66 & 97,64 & & & \\
\hline 24. & ,33 & 1,31 & 98,95 & & & \\
\hline 25. & ,26 & 1,05 & 100,00 & & & \\
\hline
\end{tabular}

Source: Authors (2021)

\subsection{Rotated factor matrix for all factors and their interpretation}

We proceed rotated factor matrix by sorting the relevant variables into factors by assigning them to the factor by their highest value. From the given rotary matrix in table No. 4 on next page we can show the relationships between variables. The factor matrix represents the 
matrix of identified factors and the correlation values between the identified factors 1 to 8 . It is the main output of the factor analysis (Hayton et. al., 2004).

Table 4. Rotated Component Matrix.

\begin{tabular}{|c|c|c|c|c|c|c|c|c|}
\hline \multirow{2}{*}{ Attributes } & \multicolumn{9}{|c|}{ Component - Factor } \\
\cline { 2 - 9 } & $\mathbf{1}$ & $\mathbf{2}$ & $\mathbf{3}$ & $\mathbf{4}$ & $\mathbf{5}$ & $\mathbf{6}$ & $\mathbf{7}$ & $\mathbf{8}$ \\
\hline 1. &, 06 &, 01 &, 00 &, 18 &, 73 &, 01 &, 18 &, 10 \\
\hline 2 &, 03 &, 08 &, 04 &, 14 &, 73 &,- 01 &, 28 &, 03 \\
\hline 3. &,- 05 &, 33 &, 15 &, 07 &, 49 &,- 01 &,- 09 &, 00 \\
\hline 4. &, 24 &, 04 &, 04 &,- 04 &, 02 &,- 01 &, 88 &,- 06 \\
\hline 5. &, 18 &, 08 &, 06 &, 07 &, 14 &,- 01 &, 63 &, 67 \\
\hline 6. &, 06 &, 07 &, 00 &, 33 &, 22 &, 01 &, 62 &, 10 \\
\hline 7. &, 05 &, 06 &,- 03 &, 77 &, 08 &, 00 &, 14 &, 02 \\
\hline 8. &, 15 &, 14 &, 03 &, 63 &, 24 &, 06 &, 06 &, 02 \\
\hline 9. & .29 & .07 & -.04 & .56 & .24 & -.01 & .07 & .01 \\
\hline 10. &, 14 &,- 10 &, 90 &,- 05 &,- 08 &, 18 &, 01 &, 04 \\
\hline 11. &,- 06 &, 16 &,- 72 &, 21 &, 17 &, 51 &, 03 &,- 02 \\
\hline 12. &, 09 &, 62 &,- 19 &, 00 &, 03 &, 04 &, 07 &, 07 \\
\hline 13. &, 22 &,- 06 &,- 21 &, 28 &, 04 &, 03 &, 47 &, 18 \\
\hline 14. & -.17 & .51 & .06 & .28 & .15 & -.02 & -.08 & -.05 \\
\hline 15. &,- 07 &, 39 &, 13 &, 42 &,- 18 &, 00 &, 10 &,- 02 \\
\hline 16. &, 58 &, 07 &, 18 &, 11 &, 02 &,- 04 &, 00 &,- 02 \\
\hline 17. &, 13 &, 23 &,- 22 &, 07 &, 52 &, 07 &,- 07 &,- 06 \\
\hline 18. &, 34 &, 29 &, 10 &,- 28 &, 27 &, 01 &,- 04 &, 01 \\
\hline 19. &, 52 &, 21 &,- 01 &, 04 &, 07 &, 02 &, 29 &, 06 \\
\hline 20. &,- 01 &, 59 &, 03 &,- 01 &, 27 &,- 05 &,- 01 &,- 01 \\
\hline 21. &, 00 &, 60 &, 13 &, 04 &, 13 &, 02 &, 16 &, 02 \\
\hline 22. &, 02 &, 12 &, 40 &, 17 &, 19 &,- 08 &,- 04 &,- 02 \\
\hline 23. &, 14 &, 45 &,- 23 &, 14 &,- 01 &, 06 &,- 07 &,- 02 \\
\hline 24. &, 62 &,- 14 &,- 09 &,- 01 &,- 05 &, 04 &, 14 &, 08 \\
\hline 25. &, 64 &,- 05 &, 05 &, 27 &, 11 &,- 02 &, 15 &,- 01 \\
\hline & & & & & & & & \\
\hline
\end{tabular}

Source: Authors (2021)

For the transformed factors 1 to 8 , a significance value was determined, which evokes the importance of influencing them when purchasing. The table shows the achieved values of the significance of these factors. The determination of significance is based on the average values determined using the liqueur scale of a specific attribute in the primary survey (Browne, 2021)

Table 4. Rotated Component Matrix.

\begin{tabular}{|c|c|}
\hline Factor & Signifiances \\
\hline Factor No. 2 & {$[(3,64+4,11+3,76+3,55+3,61) / 5]=3,73$} \\
\hline Factor No. 5 & {$[(3,32+3,22+4,29+3,43) / 4]=3,56$} \\
\hline Factor No. 3 & {$[(3,08+3,64) / 2]=3,36$} \\
\hline Factor No. 6 & {$[(3,16) / 1]=3,16$} \\
\hline Factor No. 4 & {$[(2,90+2,83+2,83+3,60) / 4]=3,04$} \\
\hline Factor No. 1 & {$[(2,37+3,41+2,13+1,42+1,92) / 5]=2,25$} \\
\hline Factor No. 8 & {$[(2,02) / 1]=2,02$} \\
\hline Factor No. 7 & {$[(1,76+2,48+1,66) / 3]=1,96$} \\
\hline
\end{tabular}

Source: Authors (2021) 


\section{Discussion}

Based on the data in table No. 4 and 5 we can move on to the interpretation of the achieved results. From the 25 variables that represented the attributes of the primary survey that we analysed by using factor analysis, The eight factors represent the relationship between the individual variables. In the following part of the interpretation of factors, the key factors will be characterized and interpreted.

Factor No.1 contains variables whose acquired value is from 0.34 to 0.64 . Factor No. 1 represents a combination of variables such as offline advertising, sustainability, Youtube activity along with cryptocurrency payments, and a newsletter purchase impulse.

Factor No. 2 contains variables whose acquired value is from 0.45 to 0.62 . Factor No. 2 represents a combination of variables such as website design, method of delivery of goods together with the possibility of online payment, reviews of companies and shopping at a wellknown seller. Based on the results of the factor analysis, it is possible to confirm that this is the most important factor that influences the customer when making a purchase. The factor is the most significant based on the determination of the significance value given in Table 6 in the section Determination of the significance value

Factor No.3 contains variables whose acquired value is from 0.40 to 0.90 . Factor 4 represents a combination of variables such as shopping in brick-and-mortar stores and the possibility of cash payment

Factor No. 4 contains variables whose acquired value is from 0.42 to 0.77 . Factor No. 4 represents a combination of variables, such as free delivery of ordered goods together with discounts, promo codes for the first purchase and the activities of merchants on social networks.

Factor No.5 contains variables whose acquired value is from 0.52 to 0.73 . Factor No. 5 represents a combination of variables, such as impulses to make a purchase from social networks, together with the possibility of purchasing using mobile applications.

Factor No.6 contains a variable whose acquired value is 0.51 . Factor no. 6 contains only one variable, online shopping.

Factor No.7 contains variables whose acquired value is from 0.47 to 0.88 . Factor 7 represents a combination of variables such as impulsive shopping, promo codes to buy from influencers and advertising contributions from influencers.

Factor No. 8 contains a variable whose acquired value is 0.80 . Factor no. 8 contains only one variable, namely reviews from influencers.

\section{Conclusion}

As a result of the research carried out by using factor analysis, we present eight identified key factors including 25 variable attributes. Based on the results, it is possible to present a key factor that influences the shopping behaviour of the $\mathrm{Z}$ generation, namely the design of the website, the importance of delivery methods together with the possibility of online payment, merchant reviews and shopping at a well-known seller.

An interesting finding is the lack of interest of Generation $\mathrm{Z}$ in the new wave of the trend of influencing shopping preferences by popular people on the Internet, called influencers.

Research shows us, that the usual attributes and activities of companies on social networks are important for the $\mathrm{Z}$ generation, while attributes that appear to be new and popular have almost no relevant effect on this generation.

\section{Acknowledgement}

This paper was supported by project VEGA 1/0518/19. 


\section{References}

1. Age composition - SR, areas, counties, districts, city, countryside, (2020, March 18). STATdat. http://statdat.statistics.sk

2. Browne, M. W. (2001). An Overview of Analytic Rotation in Exploratory Factor Analysis. Multivariate Behavioral Research, 36(1), 111-150.

3. Cismariu, C., \& Hosu, I. (2019). Generation Z and social media. In: Vlada M, Albeanu G, Istrate O, Adascalitei A, editors. Proc 14th Int Conf Virtual Learn Icvl 2019. Bucharest: Bucharest University Press (pp. 367-73).

4. Dimock, M. (2021, August 21). Where milennials end and generation $Z$ begins. PowResearch. https://www.pewresearch.org/fact-tank/2019/01/17/where-millennialsend-and-generation-z-begins

5. Dolot, A. (2018). The characteristics of Generation Z. E-Mentor, 74(74), 44-50.

6. Duris, V., Bartkova, R., \& Tirpáková, A. (2021). Principal Component Analysis and Factor Analysis for an Atanassov IF Data Set. Mathematics, 9, Art. No. 2067.

7. Gasova, K., \& Stofkova, J. (2017). Cluster cooperation in globalised world. 17th International Scientific Conference on Globalization and Its Socio-Economic Consequences, Zilina: University of Zilina (pp. 479-486).

8. Hayton, J. C., Allen, D. G., \& Scarpello, V. (2004). Factor Retention Decisions in Exploratory Factor Analysis: a Tutorial on Parallel Analysis. Organizational Research Methods, 7(2), 191-205.

9. Hebák, P. et al. (2007). Multidimensional statistical method 3. Praha: Informatorium.

10. Johnson, R. A., \& Wichern, D. W. (2007). Applied multivariate statistical analysis. New Jersey: Pearson.

11. Kubas, J., Soltes, V., \& Stofkova, Z. (2017). Modern marketing in special services. Manažment environmentálnych inovácii prostredníctvom phygitalových nástrojov, Trnava: Univerzita sv. Cyrila a Metoda v Trnave (pp. 134-141).

12. Madlenakova, L., Turska, S., \& Madlenak, R. (2019). The image of the postal company as a key attribute of the customer's purchasing behaviour. In J. Bujnak \& M. Guagliano (Eds.). Proceedings of the 13th International Scientific Conference on Sustainable, Modern and Safe Transport TRANSCOM 2019 (pp. 1088-1095).

13. Munsch, A. (2021). Millennial and generation $Z$ digital marketing communication and advertising effectiveness: A qualitative exploration. Journal of Global Scholars of Marketing Sciience, 31(1), 10-29.

14. Nadanyiova, M., Gajanova, L., \& Majerova, J. (2020). Green Marketing as a Part of the Socially Responsible Brand's Communication from the Aspect of Generational Stratification. Sustainability, 12(17), Art. No. 7118.

15. Smolka, S. (2019). Characteristics of generations of Slovak consumers. Marketing Science \& Inspirations, 14(1), 2-11.

16. Statistika PSPP. (2021, July 2). Statistika PSPP. https://statistikapspp.sk/softver-pspp/

17. Svabova, L., \& Kramarova, K. (2021). An analysis of participation factors and effects of the active labor market measure Graduate practice in Slovakia - counterfactual approach. Evaluation and Program Planning, 86, Art. No. 101917.

18. Valaskova, K., Durana, P., \& Adamko, P. Changes in Consumers' Purchase Patterns as a Consequence of the COVID-19 Pandemic. Mathematics 2021, 9, Art. No. 1788. 
19. Zilincikova, M., \& Stofkova, Z. (2021). Entrepreneurship education as a competitiveness support in the conditions of globalization. 15th International Technology, Education and Development Conference, Valencia: IATED, INTED Proceedings (pp. 7833-7840). 